\title{
INTRADISCAL ELECTROTHERMAL THERAPY (IDET) FOR TREATMENT OF Chronic lumbar Discogenic Pain: A Minimum 2-Year Clinical OUTCOME Study
}

\author{
Michael S. Lee, MD, Grant Cooper, MD, Gregory E. Lutz, MD, Christopher Lutz, MD, and Hoyman M. Hong, MD
}

Objective: To determine the long-term efficacy of IDET in the treatment of chronic lumbar discogenic pain.

Design: Prospective case series clinical outcome study.

Methods: IDET was performed on 62 consecutive patients with chronic discogenic pain of greater than 6 months duration and consecutively enrolled in a non-randomized prospective case series outcome study. Outcome measures included visual numeric pain scale (VNS) for low back (LB) and lower extremity (LE) pain, Roland-Morris disability scale (RM), and North American Spine
Society (NASS) patient satisfaction index. Outcome success was defined as a change of more than 2 points on VNS and RM as well as a positive NASS satisfaction response. Data were collected at baseline and post-procedure at 1, 3, and 6 months and then annually for up to 4 years.

Results: Fifty-one out of 62 patients (82\%) were available for a minimum of 2 -year follow-up. Average age was 41.4 years; average symptom duration was 46 months; and average follow-up was 34 months. Overall, there was statistically significant improvement in LB-VNS, RM, and LE pain scores of $3.2,6.6$, and $2.3(\mathrm{p}<0.001)$, respectively. Twenty-seven of 51 (53\%) patients demonstrated clinically significant VNS and RM improvements of greater than 2. On NASS index, $63 \%(32 / 51)$ responded positively. Neither the number of disc levels treated nor the insurance status of patients made any difference in outcome.

Conclusion: IDET appears to be an effective treatment for chronic lumbar discogenic pain in a well-selected group of patients with favorable long-term outcome.

Keywords: Intradiscal, electrothermal treatment, lumbar discogenic pain
An estimated 10 billion dollars is spent for treatment of chronic low back pain (LBP), the number one cause of disability in people under age $45(1,2)$. There is a considerable debate, however, on various treatment options for patients with LBP. While the majority of these patients with lumbar pain improve in 3 months, it has been estimated that approximately $5 \%$ will have chronic disabling low back pain and up to $60 \%$ will have recurrent episodes of lumbar pain (1). Historically, treatment options were limited and nonspecific given our poor understanding of the causes of LBP.

New advances in technology using diagnostic spinal injection techniques have provided significant insight into the numerous pain-generating structures of the lumbar spine (3). With greater understanding of the specific etiologies of LBP, a single anatomic lesion can often be found with up to $40 \%$ of cases caused by a painful degenerative intervertebral disc (4).

From Hospital for Special Surgery, New York, New York. Address Correspondence: Gregory E. Lutz, MD, Department of Physiatry, Hospital for Special Surgery, 535 East 70 ${ }^{\text {th }}$ St, New York, NY 10021. E-mail: lutzg@hss.edu

Funding: There was no external funding in preparation of this manuscript.
Numerous studies have shown that nociceptive fibers, either from the posterior longitudinal ligament or the lamina of the outer annulus, penetrate through to the inner annulus in diseased discs and can be a source of discogenic pain (5-12).

Conservative medical treatment options for patients with chronic discogenic pain have included trials of exercise with manual therapy, lumbar corsets, back school, oral medication, epidural steroid injections, intradiscal steroid injections and lifestyle modifications. Despite the best non-operative treatment there remain patients who continue to suffer with symptoms that adversely impact their quality of life and their ability to maintain or return to gainful employment. These patients are often left with the option of living with their disabling pain or undergoing a surgical intervention. While spinal fusion is considered the "gold standard" of treatment, this procedure carries the potential for significant patient morbidity and mortality with failure rates as high as $40 \%$ (13). There is some evidence to support the use of fusions for segmental instability, yet little scientific basis support the use of lumbar fusion with or without instrumentation for chronic discogenic pain (14).
The emergence of minimally invasive treatment options has provided another tier of treatment options for patients and clinicians. For example, a percutaneous intradiscal laser nucleotomy is an ablative procedure that uses a laser to vaporize the nucleus pulposus causing a reduction in disc volume $(15,16)$. This procedure is typically used to ameliorate radicular greater than axial pain usually from a contained disc protrusion. Other non-ablative intradiscal heating techniques can be accomplished through using a radiofrequency probe $(17,18)$ or a thermal resistive spinal catheter $(19,20)$. The proposed mechanisms of action of these techniques are collagen modulation, cauterization of granulation tissue, deactivation of inflammatory agents and possibly annular denervation. Targeted thermal therapy has been shown to induce collagen fibril shrinkage at temperatures greater than 60 degrees Celsius and destruction of neural tissue at temperatures above 42-45 degrees Celsius (21-25). Intradiscal electrothermal therapy (IDET) is an intradiscal annular heating method that has been shown to produce temperatures sufficient to cause nerve fiber death (19) as well as collagen denaturation (26). In addition, no adverse biomechanical al- 
teration or destabilization, in vitro, has been reported after IDET procedure in lumbar spinal motion segments (27).

In order to elucidate the long-term effects of IDET treatment with discogenic pain, we asked the following research questions in this prospective clinical outcome study: (1) What are the clinical and functional outcomes, (2) Is there a difference between single-level and multi-level IDET outcomes, (3) Are there any negative outcome predictors, (4) Does a patient's insurance status affect clinical outcome results?

\section{Methods}

Patients were recruited from an academic-affiliated private physiatric practice. Our inclusion criteria were the following: constant moderate to severe low back pain > 6 months; sitting $>$ standing pain; normal neurologic examination; failure of conservative care (i.e. trial of nonsteroidal anti-inflammatory, epidural injection, and a comprehensive spine rehabilitation program); MRI or CT scan demonstrating no neural compressive lesion; positive discogram with post-CT image demonstrating internal disc disruption, focal annular tear with or without disc protrusion of $<5 \mathrm{~mm}$. Patients were excluded based on the following: se- vere disc space narrowing $>50 \%$ (in comparison to a normal disc); disc extrusion $(>5 \mathrm{~mm})$ or a sequestered fragment; severe spinal stenosis $(<10 \mathrm{~mm}$ sagittal canal diameter); Spondylolisthesis > grade I; and segmental instability ( $>4 \mathrm{~mm}$ translation on standing flexion/extension radiographs). We did not exclude patients with a prior history of a microdiscectomy or spinal fusion. Insurance status of each patient was recorded. All patients signed informed consent approved by the institutional review board.

\section{Outcome Measures}

Each patient was enrolled prospectively. Questionnaires administered by an independent observer at baseline and post-procedure at 1, 3, 6 months and annually thereafter. The questionnaires included the following: low back (LB) and lower extremity (LE) visual numeric pain scale (VNS), from 0-10 where 0 equaled no pain and 10 equaled the most severe pain ever experienced; Roland Morris disability (RM) evaluation and North American Spine Society (NASS) patient satisfaction index. History of oral analgesic usage was obtained.

\section{Fluoroscopically Guided Pressure Con- trolled Lumbar Discography}

Intravenous access was obtained. No sedation was used. The patient received pre-procedural IV antibiotics, 1 gram Ancef, and intradiscal antibiotics at each level studied. Sterile prep, drape and local anesthetic were administered to the patient in prone position. Under fluoroscopic guidance using a standard extrapedicular double needle discographic approach, a 25 -gauge needle was advanced through the 20-gauge introducer spinal needle into the midportion of the disc. Placement was confirmed in multiple fluoroscopic projections. Contrast dye (Omnipaque 180) (Nycomed Inc, Princeton, New Jersey) was injected using the Intellisystem Inflation Monitor (Merit Medical System Inc, South Jordan, Utah). The patient's opening and maximal pressure attained, pain response, volume of injectate, and internal disc architecture were recorded. Discs were classified as either chemical (concordant pain at $<15$ psi above baseline opening pressure) or mechanical ( $>15$ psi to 50 psi above baseline opening pressure) sensitized using the Derby Classification System (28). Thereafter, the patient was taken for a post-discography CT scan of the lumbar spine and the discs was classified using the Dallas Discogram Classification System (29) (Fig. 1). If the results of the discogram were positive and the inclusion criteria were met, the patient was scheduled for IDET at a later date.

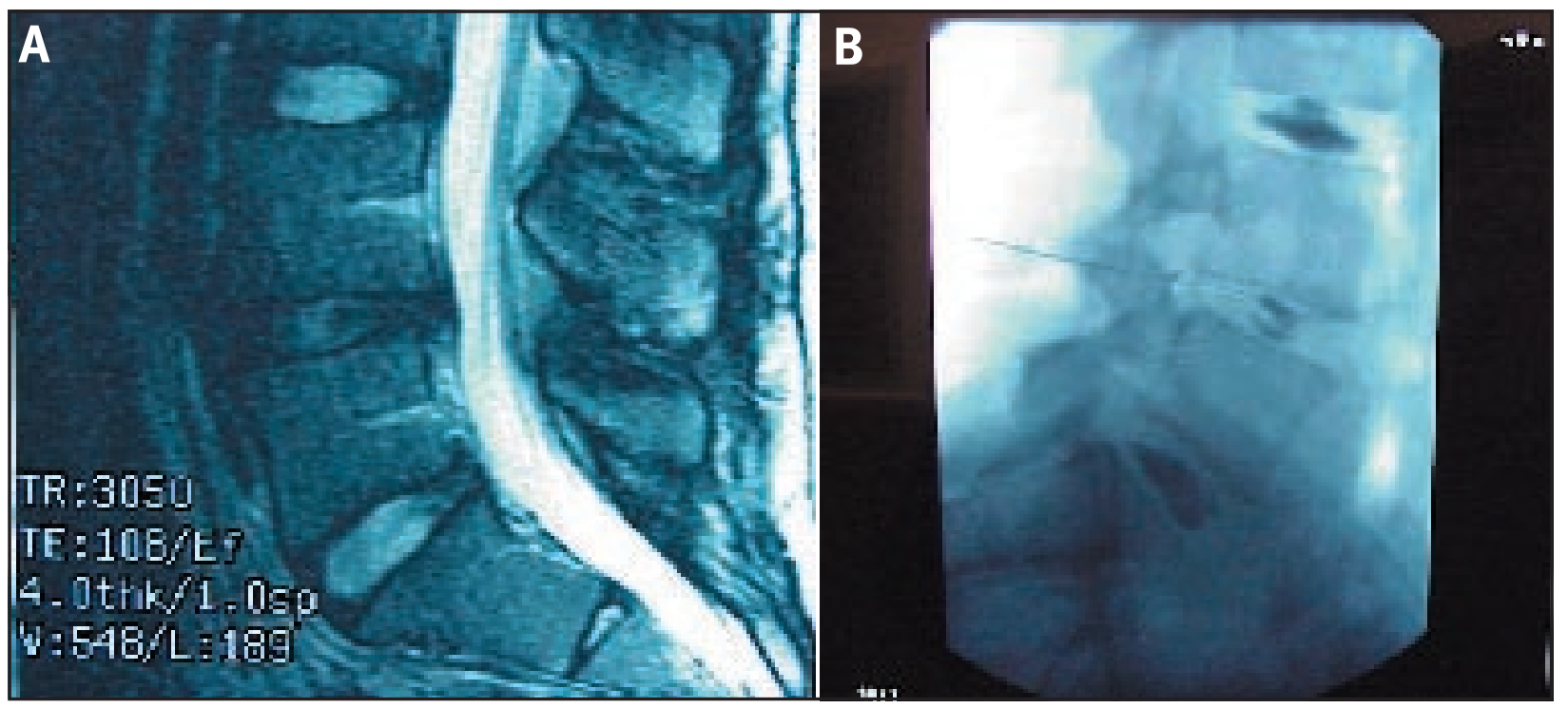

Fig. 1. A 24-year old dancer with back pain. T-2 weighted MRI showed degenerated intervertebral disc at L4-5 with relatively well-preserved disc height (a). Patient underwent pressure controlled provocative lumbar discography (b). The patient experienced severe concordant pain at L4/5 with low pressures and volumes consistent with a chemically sensitized disc. AP and lateral fluoroscopic images at L4/5 demonstrating abnormal disc architecture with annular tear. Both the L3/4 and L5/S1 discs were normal. 


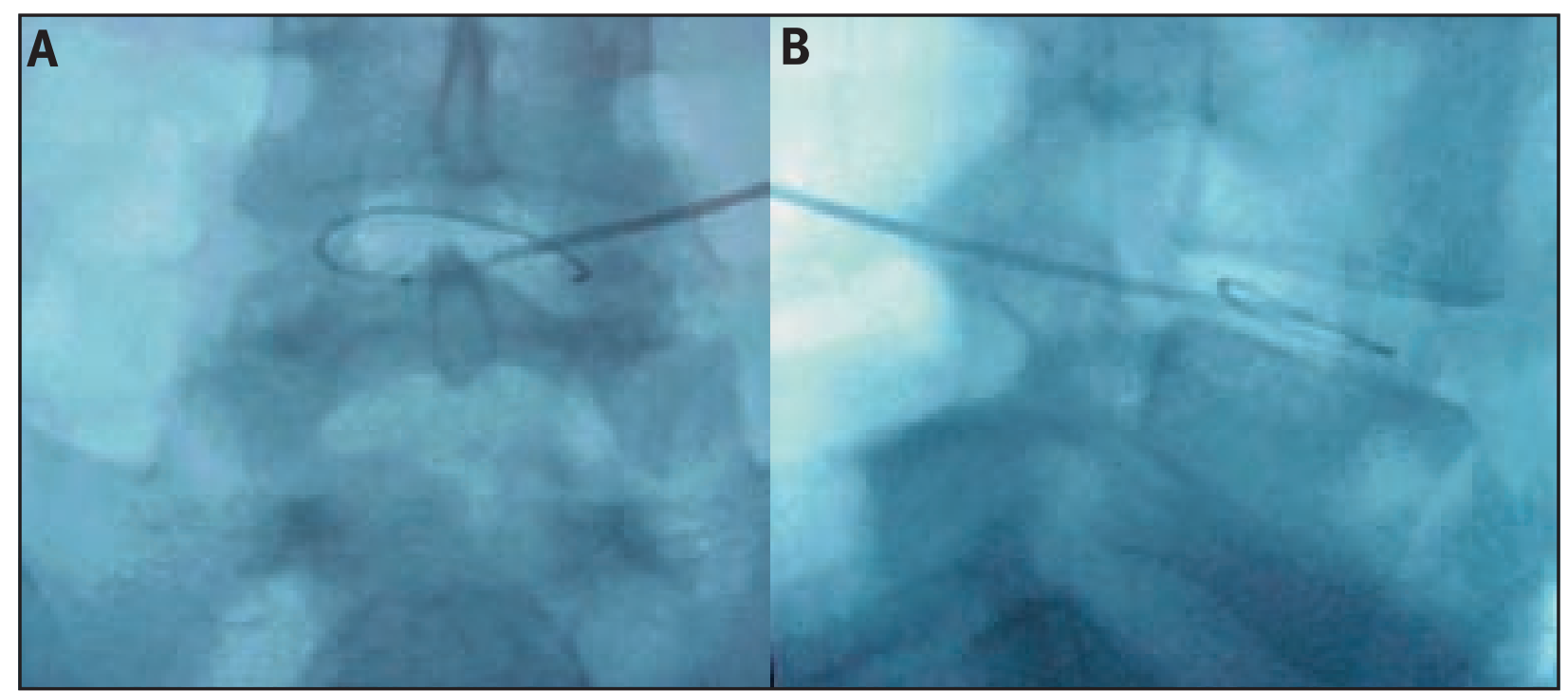

Fig. 2. IDET was performed in the above patient at L4/5. AP and lateral fluoroscopic images demonstrate proper catheter placement in the posterior annulus across midline covering the annular tear. There was significant clinical improvement more than 2 years out from the procedure.

Fluoroscopically Guided Intradiscal Electrothermal Therapy (IDET)

Intravenous conscious sedation was administered by an anesthesiologist present during the procedure. Sterile prep, drape and local anesthetic were administered to the patient in the prone position. Under fluoroscopic guidance, a 17-gauge introducer needle was advanced into the mid-portion of the disc using the standard extrapedicular discographic technique. Proper placement of the introducer needle was confirmed with anterior-posterior and lateral fluoroscopic projections. The spine catheter (SpineCATH; ORATEC Interventions, Inc., Menlo Park, California) was navigated through the introducer needle to the posterior annular wall past the midline. Correct placement was confirmed with anterior-posterior and lateral fluoroscopic projections (Fig. 2). The standard high heating protocol was used in the majority of patients which starts at 65 degrees Centigrade and is gradually increased to 90 degrees Centigrade over 12.5 minutes. Heating continued at 90 degrees Centigrade for 4 minutes for a total of 16.5 minutes. After the procedure, the catheter and introducer needle were removed and the patient was taken to recovery room where he or she was discharged home once they had stabilized.

Post procedure management (weeks 1-6) consisted of bracing using a semirigid lumbosacral orthosis. Patients were instructed to avoid prolonged sitting (> 30 minutes) without changing positions. No heavy lifting $>20$ pounds or repetitive bending were allowed. They were allowed to walk on flat surfaces and in the pool, swim backstroke or freestyle using a snorkel to minimize repetitive lumbar rotation. Oral analgesia was accomplished for the first two weeks with hydrocodone as needed. Thereafter, the patients used over-the-counter medications as needed. A few patients required a short course (24 weeks) of a non-steroidal anti-inflammatory medication to further manage their post-procedure pain. Weeks 6-12 consisted of restarting neutral spine lumbar stabilization exercises and progressing to spine safe strengthening and conditioning exercises as tolerated. At 12 weeks the patients were usually completely independent with their exercise program and without restrictions.

\section{Statistical Methods}

Clinical improvement was defined as change of more than 2 points on VNS and Roland Morris as well as a positive NASS satisfaction response. Statistical analysis was performed for descriptive statistics. Mean scores and demographics of patients were evaluated using independent group t-tests. Paired two-tailed ttests were used to compare pre and post VNS and RM scores with analysis of variance, ANOVA, to compare subgroups. Chi-square test was used to compare the frequency of oral analgesic usage. A p-value $<0.05$ was considered statistically significant.

\section{Results}

In this study, 62 patients met our inclusion criteria and underwent the IDET procedure from 1999 to 2001, and 51/62 patients $(82 \%)$ were available for a minimum of 24 months follow-up. Eleven patients who had relocated out of area without a forwarding address or telephone number were lost to follow-up. There were no peri- or post-procedural complications of dural puncture, infection or nerve injury. There were 4 patients with history of spondylolisthesis, 3 patients who had previously undergone microdiscectomy, and 4 patients with history of prior spinal fusion.

Subjects were treated with IDET at single or multiple levels using standard heating protocol and discographic technique. There was a male: female ratio of 29:22; average age was 41.4 years (range 18-60 years); average symptom duration was 46 months (range 6-180 months); and average follow-up was 34 months (647 months) (Table 1). There were a total of 70 levels treated in the 51 patients available for follow-up. The most common level treated was L4-5 (37/70) accounting for $52.8 \%$ of all levels treated, followed by L5-S1 $(24 / 70,34.3 \%)$ and L3$4(9 / 70,12.9 \%)$. Thirty-two patients underwent single-level treatment versus 19 
patients who received multi-level treatment (Table 1).

Overall, there was statistically significant improvement in LB VNS score, RM score, and LE pain scores of 3.2, 6.6, and $2.3(\mathrm{p}<0.001)$, respectively. Twenty-seven out of $51(53 \%)$ patients demonstrated clinically significant VNS and RM improvements of greater than 2. On NASS patient satisfaction index, 63\% (32/51) responded positively and would undergo the procedure again for the same result while $8 \%(4 / 51)$ stated the procedure helped yet would not undergo the procedure again for the same result. Both single level $(n=32)$ and multilevel IDET $(n=19)$ demonstrated improvements in pain and function $(\mathrm{p}<0.001$, Table 2$)$. There was no difference in age, symptom duration, follow-up period, and pre-IDET pain or RM scores between single and multi-level groups $(\mathrm{p}>0.05)$. Workman's compensation and no-fault $(\mathrm{n}=20)$ group $(\mathrm{p}<0.05)$ improved equally when compared to self-pay and traditional insurance group $(n=41)$ (Table 3). Again, there was no difference in age, follow-up period, and preIDET pain or RM scores between the two groups $(p>0.05)$. The workman's compensation and no-fault group, however, had shorter pain duration period before undergoing IDET treatment (33.2 \pm 32.1 vs. $54.3 \pm 39.9$ months, $\mathrm{p}=0.05)$. Patients who had previously undergone a microdiscectomy $(n=3)$ responded favorably with mean LB VNS, RM, and LE VNS improvement of $6.3,20.7$, and $8.0(\mathrm{p}<0.05)$, respectively. Those with spondylolisthesis $(\mathrm{n}=4)$ did not improve $(\mathrm{P}>0.05$, Table 2$)$. Other subpopulations analyzed including age, gender, symptom duration, annular degeneration grade, intervertebral level treated and chemical or mechanical sensitivity demonstrated no statistical difference in outcome.

A total of 7 patients (14\%) underwent additional therapeutic procedures during the follow-up period. Only 2 out of the 51 patients (4\%) underwent a spinal fusion procedure. Both patients who underwent a spinal fusion reported no improvement in their symptoms or function. Two patients underwent a repeat IDET procedure during the follow-up period and both patients reported clinical improvements before and after the repeat IDET. Nucleoplasty decompression procedure was performed on 2 patients and radiofrequency medial branch de-

Table 1. Patient demographics, levels treated and overall results (Mean \pm Std. Dev.)

\begin{tabular}{|c|c|c|c|c|c|}
\hline \multicolumn{2}{|c|}{ Total Patients } & \multicolumn{4}{|l|}{$\mathrm{n}=51$} \\
\hline \multicolumn{2}{|c|}{ Males } & \multicolumn{4}{|l|}{$n=29$} \\
\hline \multicolumn{2}{|c|}{ Females } & \multicolumn{4}{|c|}{$\mathrm{n}=22$} \\
\hline \multirow{2}{*}{\multicolumn{2}{|c|}{ Mean Age }} & \multicolumn{4}{|c|}{41.4 (Range 18-6o) } \\
\hline \multirow{2}{*}{\multicolumn{2}{|c|}{$\begin{array}{l}\text { Mean Symptom Duration } \\
\text { Mean Follow-up }\end{array}$}} & \multirow{2}{*}{\multicolumn{4}{|c|}{46 Months (Range 6-180) }} \\
\hline & & & & & \\
\hline \multicolumn{2}{|c|}{ Levels treated } & Frequency & $\%$ total & & \\
\hline \multicolumn{2}{|c|}{ L3-4 } & $2 / 51$ & $3.9 \%$ & & \\
\hline \multicolumn{2}{|l|}{ L4-5 } & $18 / 51$ & $35.4 \%$ & & \\
\hline \multicolumn{2}{|l|}{ L5-S1 } & $12 / 51$ & $23.5 \%$ & & \\
\hline \multirow{2}{*}{\multicolumn{2}{|c|}{$\begin{array}{l}\text { L3-4, L4-5 } \\
\text { L4-5, L5-S1 }\end{array}$}} & $7 / 51$ & $13.7 \%$ & & \\
\hline & & $12 / 51$ & $23.5 \%$ & & \\
\hline & & PRE-IDET & POST-IDET & CHANGE & p-value \\
\hline LB-VNS & $(n=51)$ & $7.9 \pm 1.3$ & $4.7 \pm 3.0$ & $-3.2 \pm 3.0$ & $<0.001$ \\
\hline & $(n=50)$ & $15.4 \pm 5.3$ & $8.8 \pm 7.5$ & $-6.6 \pm 7.5$ & $<0.001$ \\
\hline LE-VNS & $(n=51)$ & $5.0 \pm 3.6$ & $2.7 \pm 3.2$ & $-2.3 \pm 4.1$ & $<0.001$ \\
\hline
\end{tabular}

Table 2. Outcome results by subgroups (Mean \pm Std. Dev.)

\begin{tabular}{|c|c|c|c|c|}
\hline Single Level $(n=32)$ & PRE-IDET & POST-IDET & CHANGE & p-value \\
\hline $\begin{array}{l}\text { LB-VNS } \\
\text { RM } \\
\text { LE-VNS }\end{array}$ & $\begin{array}{l}7.9 \pm 1.2 \\
15.2 \pm 5.1 \\
5 \cdot 4 \pm 3 \cdot 3\end{array}$ & $\begin{array}{l}4.7 \pm 2.8 \\
8.6 \pm 7.0 \\
2.8 \pm 3.0\end{array}$ & $\begin{array}{l}3.2 \pm 2.7^{\star \star} \\
6.6 \pm 7.3^{\#} \\
2.6 \pm 3.0^{\star}\end{array}$ & $\begin{array}{l}<0.001 \\
<0.001 \\
<0.001\end{array}$ \\
\hline \multicolumn{5}{|l|}{ Multi-Level $(n=20)$} \\
\hline $\begin{array}{l}\text { LB-VNS } \\
\text { RM } \\
\text { LE-VNS }\end{array}$ & $\begin{array}{l}7 \cdot 9 \pm 1.6 \\
15 \cdot 7 \pm 5 \cdot 9 \\
4 \cdot 5 \pm 4 \cdot 0\end{array}$ & $\begin{array}{l}4.7 \pm 3.5 \\
9.1 \pm 8.4 \\
2.6 \pm 3.7\end{array}$ & $\begin{array}{l}3.2 \pm 3.5^{* *} \\
6.6 \pm 8.1 \# \\
1.9 \pm 5.6^{*}\end{array}$ & $\begin{array}{l}<0.001 \\
<0.001 \\
<0.001\end{array}$ \\
\hline Spondylolisthesis $(n=4)$ & PRE-IDET & POST-IDET & CHANGE & p-value \\
\hline $\begin{array}{l}\text { LB-VNS } \\
\text { RM } \\
\text { LE-VNS }\end{array}$ & $\begin{array}{l}7.3 \pm 0.5 \\
12.0 \pm 8.1 \\
5.0 \pm 3.4\end{array}$ & $\begin{array}{l}5.0 \pm 2.2 \\
9.3 \pm 6.2 \\
4.5 \pm 3.7\end{array}$ & $\begin{array}{l}-2.3 \\
-2.7 \\
-0.5\end{array}$ & $\begin{array}{l}0.08 \\
0.34 \\
0.60\end{array}$ \\
\hline
\end{tabular}

** $p=0.97$, No statistically significant difference between single vs multilevel changes in LB-VNS $\# p=0.99$, No statistically significant difference between single vs multilevel changes in RM

$* p=0.57$, No statistically significant difference between single vs multilevel changes in LE-VNS

Table 3. Outcome results by insurance subgroups (mean \pm Std. Dev.)

\begin{tabular}{lllll}
\hline \multicolumn{4}{l}{ Workman's Compensation and No-Fault $(n=20)$} & \\
\\
LB-VNS & PRE-IDET & POST-IDET & CHANGE & p-value \\
RM & $8.2 \pm 1.0$ & $5 \cdot 3 \pm 2.7$ & $2.9 \pm 2.5^{\star \star}$ & $<0.001$ \\
LE-VNS & $15.8 \pm 5.3$ & $11.4 \pm 7.8$ & $4.5 \pm 6.6 \#$ & $<0.001$ \\
& $4.8 \pm 3.9$ & $2.9 \pm 3.1$ & $1.9 \pm 4.5^{*}$ & $<0.001$
\end{tabular}

Self-Pay and Traditional Insurance $(n=41)$

\begin{tabular}{lllll|} 
& PRE-IDET & POST-IDET & CHANGE & p-value \\
LB-VNS & $7.8 \pm 1.5$ & $4.4 \pm 3.2$ & $3.3 \pm 3.3^{\star \star}$ & $<0.001$ \\
RM & $15.1 \pm 5.4$ & $7.9 \pm 7.9$ & $7.9 \pm 7.9 \#$ & $<0.001$ \\
LE-VNS & $5.2 \pm 3.4$ & $2.5 \pm 3.9$ & $2.5 \pm 3.9^{\star}$ & $<0.001$
\end{tabular}

** $p=0.66$, No statistically significant difference between insurance types in LB-VNS improvement. $\# p=0.12$, No statistically significant difference between insurance types in RM improvement.

* $p=0.62$, No statistically significant difference between insurance types in LE-VNS improvement.

nervation procedure was performed on 3 patients. In terms of oral analgesic usage, $68 \%(30 / 44)$ reported using less or no pain medications $(\mathrm{p}<0.05)$, and $25 \%(11 / 44)$ reported using same amount. Only $7 \%(3 / 44)$ of patients were using more oral pain medication at the time of our last follow-up. 


\section{DisCUSSION}

This prospective outcome study assessed the clinical efficacy of IDET in a series of patients enrolled according to strict inclusion/exclusion criteria. The results of this long-term study demonstrate a statistically and clinically significant improvement in patients' pain level, functional capacity, and patient satisfaction of the outcome. Overall, patients demonstrated statistically significant mean VNS and RM improvement. This improvement was true for both low back and lower extremity pain. Of these, 53\% reported improvement in VNS and RM score of greater than 2 . On NASS patient satisfaction index, $63 \%$ responded positively and would undergo the procedure again for the same result. Our findings mirror the success rates of other studies assessing IDET's efficacy shown to have 50 to $74 \%$ success rates at one and two year followup period (30-36).

Subgroup analysis revealed several interesting findings. The number of disc levels treated with IDET had no effect on clinical outcome. No negative outcome predictors were found except for the presence of spondylolisthesis. In fact, two out of 4 of patients with spondylolisthesis underwent spinal fusion during our follow-up period. This may not be surprising given abnormal segmental movements and loading observed in these patients with spondylolisthesis. While our number is small $(\mathrm{n}=4)$, a larger population of patients with spondylolisthesis revealed similar findings in a 1 -year followup study (37). Involvement in workman's compensation and no-fault insurance did not adversely affect clinical outcome after IDET. Those patients who had a prior microdiscectomy did surprisingly well and therefore should not be excluded from consideration for this procedure. Fourteen percent (7/51) required additional therapeutic procedures including nucleoplasty, medial branch radiofrequency denervation, and repeat IDET procedures. In our patient population, only $4 \%$ $(2 / 51)$ of the patients required spinal fusion when all patients were considered a spinal fusion candidate before receiving the IDET treatment. Both of these patients did poorly with IDET treatment, and spinal fusion did not improve their pain or function.

The strengths of this study include a large of number of subjects with a long- term follow-up period. To the best of our knowledge, this study has the longest average follow-up period of 34 months among the published studies. Strict inclusion and exclusion criteria were used to enroll subjects. In addition, we reported on the efficacy of IDET procedure in managing lower extremity pain associated with chronic disc disruption. The improvement shown for lower extremity pain may in fact be higher since 14 of 51 patients had no lower extremity pain on initial presentation. This is also the first study to report on clinical outcome and status of patients who did not improve clinically with IDET procedure.

This study also has several important limitations. There was patient selection bias in excluding those with significantly diminished disc space. This was done for technical reasons when we initially proposed our study. We may have unknowingly selected a positive prognostic factor for those undergoing IDET procedure. Those with severe disc space narrowing may have other coexisting conditions such as facet disease and other spondylolytic changes that could be a pain generating nidus. Another limitation of this study is lack of control group, historic or placebo. Conducting a blinded, randomized placebo-controlled study may be prohibitively expensive and logistically difficult in a private practice setting. To our knowledge there is only one such study, yet to be published in a peer-reviewed journal, which showed moderate improvement in pain scale after a relatively short-term follow-up period (38). Additionally, this study provides no insight into understanding IDET's mechanism of action and what heating protocols will produce the maximum therapeutic effect with minimal patient morbidity.

\section{Conclusion}

IDET appears to be a safe and potentially an effective treatment with longterm clinical efficacy for chronic lumbar discogenic pain in a well-selected group of patients. There was a clear reduction in the use of oral analgesics. A post-surgical history of microdiscectomy should not exclude treatment with IDET. Clearly, further research is needed in randomized placebo-controlled studies to more definitively evaluate clinical efficacy of IDET in treating chronic lumbar discogenic pain and elucidate mechanism of action of intradiscal electrothermal treatment.

\section{Author Affiliation: \\ Michael S. Lee, MD}

Hospital for Special Surgery

535 East 70th St.

New York, NY 10021

E-mail: leemi@hss.edu

Grant Cooper, MD

Hospital for Special Surgery

535 East 70th St.

New York, NY 10021

Gregory E. Lutz, MD

Physiatrist-in-Chief

Hospital for Special Surgery

535 East 70th St.

New York, NY 10021

E-mail:lutzg@hss.edu

Christopher Lutz, MD

Hospital for Special Surgery

535 East 70th St.

New York, NY 10021

E-mail: lutzc@hss.edu

Hoyman M. Hong, MD

Hospital for Special Surgery

535 East 70th St

New York, NY 10021

\section{REFERENCES}

1. Anderson G, Svenson H, Oden A. The intensity of work recovery in low back pain. Spine 1983; 8:880-885.

2. Frymoyer JW, Cats-Buril WL. An overview of the incidences and costs of low back pain. Clin Orthop North Am 1991; 22:263-271.

3. O’Neill C, Derby R, Kenderes L. Precision injection techniques for diagnosis and treatment of lumbar disc disease. Sem Spine Surg 1999; 11:104-118.

4. Schwarzer AC, Aprill CN, Derby R. The prevalence and clinical features of internal disc disruption in patients with chronic low back pain. Spine 1995; 20:1878-1883.

5. Bogduk N, Tynan W, Wilson A. The nerve supply to the human intervertebral discs. J Anat 1981; 132: 39-56.

6. Kontinnen YT, Gronbald M, Anitt-Poika I. Neurohistochemical analysis of peridiscal nocicoceptive neural elements. Spine 1990; 15:383-386.

7. McCarthy PW, Carruthers B, Martin D. Immunohistochemical demonstration of sensory nerve fibers and endings in lumbar intervertebral discs of the rat. Spine 1991; 16:653-655.

8. Coppes MH, Marani E, Thomeer RT et al. Innervation of "painful" lumbar discs. Spine 1997; 22:2342-2350.

9. Freemont AJ. Nerve ingrowth into diseased intervertebral disc in chronic back pain. Lancet 1997; 350:178.

10. Gunzburg R, Parkinson R, Moore R et al. A cadaveric study comparing discogra- 
phy, magnetic resonance imaging, histology and mechanical behavior of the human lumbar disc. Spine 1992; 17:417-426.

11. Osti OL, Vernon-Roberts, Moore $\mathrm{R}$ et al. Annular tears and disc degeneration in the lumbar spine. J Bone Joint Surg Br 1992; 74:678-682.

12. Osti OL, Vernon-Roberts, Fraser RD. 1990 Volvo Award in experimental studies. Anulus tears and intervertebral disc degeneration. An experimental study using an animal model. Spine 1990; 15:762-767.

13. Turner JA, Ersek M, Herron L. Patient outcomes after lumbar spine fusions. JAMA 1992; 268:907-911.

14. Gibson AJN, Grant IC, Waddell G. The Cochrane Review of surgery for lumbar disc prolapse and degenerative lumbar spondylosis. Spine 1999; 24:1820-1832.

15. Yonezawa T, Onomura T, Kosaka R. The system and procedures of percutaneous laser nucleotomy. Spine 1990; 15:1175-1185.

16. Choy DSJ, Ascher PW, Saddekni S. Percutaneous laser disc decompression. A new therapeutic modality. Spine 1992; 17: 949-956.

17. Sluijter ME. The use of radiofrequency lesions for pain relief in failed back patients. Int Disabil Stud 1988; 10:47-43.

18. Sluijter ME, Vonklerf $M$. The radiofrequency lesion of the lumbar intervertebral disc. Poster Presentation at the Annual International Pain Conference. Atlanta, Georgia, August 1994.

19. Saal JS, Saal JA. A novel approach to painful disc derangement: Collagen modulation with a thermal percutaneous navigable catheter: A prospective trial. Presented at NASS Thirteenth Meeting, San Francisco CA, October 1998.

20. Saal JS, Saal JA. Management of chronic discogenic low back pain with a thermal intra- discal catheter. Spine 2000; 25: 382-388.

21. Wall MS, Deng XH, Torzilli P et al. Therma modification of collagen. J Shoulder Elbow Surg 1999; 8:339-344.

22. Hecht P, Hayashi K, Cooley AJ et al. The thermal effect of monopolar radiofrequency energy on the properties of joint capsule: An in vivo histologic study using a sheep model. Am J Sports Med 1998; 26: 808-814.

23. Troussier B, Lebas JF, Chirossel JP et al. Percutaneous intradiscal radiofrequency thermocoagulation: a cadaveric spine study. Spine 1995; 20:1713-1718.

24. Cosman ER, Nashold B, Ovelman-Levitt. Theoretical aspects of radiofrequency lesions in the dorsal root entry zone. Neurosurgery 1984; 15:945-955.

25. Strohbehn JW. Temperature distributions from interstitial RF electrode hyperthermia systems: Theoretical predictions. Int / Radiat Oncol Biol Phys 1983; 9:1655-1667.

26. Shah RV, Lutz GE, Lee J et al. Intradis kal electrothermal therapy: A preliminary histology study. Arch Phys Med Rehabil 2001; 82:120-122.

27. Lee J, Lutz GE, Campbell D et al. Stability of the lumbar spine after intradiscal electrothermal therapy. Arch Phys Med Rehabil 2001; 82:1230-1237.

28. Derby R, Howard MW, Grant JM et al. The ability of pressure-controlled discography to predict surgical and nonsurgical outcomes. Spine 1999; 24: 364-372.

29. Sachs B, Vangaranta $H$, Spivey $M$ et al. Dallas Discogram Description: A new classification of $\mathrm{CT} /$ discography in low back disorders. Spine 1987; 12:287-284

30. Karasek M, Bogduk N. Twelve-month followup of a controlled trial of intradiscal thermal anuloplasty for back pain due to internal disc disruption. Spine 2000; 25:2601-2607.
31. Saal JA, Saal JS. Intradiscal electrotherma treatment for chronic discogenic low back pain. Spine 2000; 25:2622-2627.

32. Derby R. Intradiscal electrothermal annuloplasty. Presented at Meeting of North American Spine Society, San Francisco, CA, 1998.

33. Derby $R$, Eek $B$, Chen $Y$ et al. Intradiscal Electrothermal Annuloplasty (IDET): A novel approach for treating chronic discogenic back pain. Neuromodulation 2000 ; 3:82-88.

34. Bogduk N, Karasek M. Two-year follow-up of a controlled trial of intradiscal electrothermal annuloplasty for chronic low back pain resulting from internal disc disruption. Spine / 2002; 2:343-350.

35. Saal JA, Saal JS. Intradiscal electrothermal treatment of chronic discogenic low back pain: Prospective outcome study with a minimum 2-year follow-up. Spine 2002; 27:966-974.

36. Lutz C, Lutz GE, Cooke P. Treatment of chronic lumbar discogenic pain with intradiscal electrothermal therapy (IDET): A prospective outcome study. Arch Phys Med Rehabil 2003; 84:23-28.

37. Hong HM, Lutz GE, Lutz C. Treatment of chronic lumbar discogenic pain with intradiscal electrothermal therapy (IDET). Presented at the American Academy of Physical Medicine and Rehabilitation. Orlando, Florida, 2002.

38. Pauza K, Howell S, Dreyfuss P et al. A randomized, double-blind, placebo controlled trial evaluating the efficacy of intradiscal electrothermal annuloplasty (IDET) for the treatment of chronic discogenic low back pain: 6-months outcomes. Presented at the $10^{\text {th }}$ Annual Scientific Meeting of the International Society for Spinal Injection, Austin, Texas, 2002. 